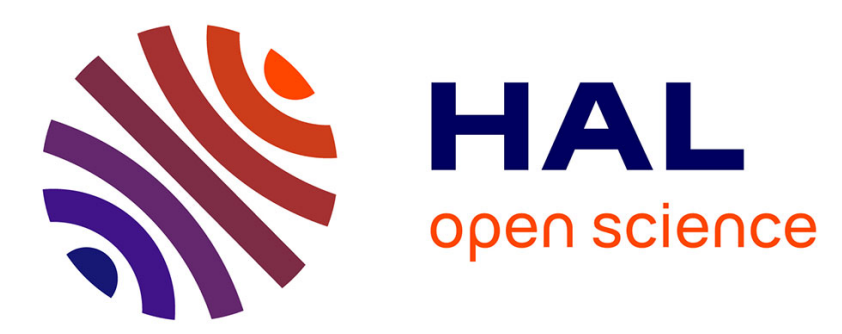

\title{
Complementation of Yeast Arc1p by the p43 Component of the Human Multisynthetase Complex does not Require its Association with Yeast MetRS and GluRS
}

\author{
Marie-Pierre Golinelli-Cohen, Adriana Zakrzewska, Marc Mirande
}

\section{- To cite this version:}

Marie-Pierre Golinelli-Cohen, Adriana Zakrzewska, Marc Mirande. Complementation of Yeast Arc1p by the p43 Component of the Human Multisynthetase Complex does not Require its Association with Yeast MetRS and GluRS. Journal of Molecular Biology, 2004, 340 (1), pp.15 - 27. 10.1016/j.jmb.2004.04.040 . hal-01873532

\section{HAL Id: hal-01873532 \\ https://hal.science/hal-01873532}

Submitted on 8 Oct 2019

HAL is a multi-disciplinary open access archive for the deposit and dissemination of scientific research documents, whether they are published or not. The documents may come from teaching and research institutions in France or abroad, or from public or private research centers.
L'archive ouverte pluridisciplinaire HAL, est destinée au dépôt et à la diffusion de documents scientifiques de niveau recherche, publiés ou non, émanant des établissements d'enseignement et de recherche français ou étrangers, des laboratoires publics ou privés. 


\section{Complementation of Yeast Arc1p by the p43 Component of the Human Multisynthetase Complex does not Require its Association with Yeast MetRS and GluRS}

\section{Marie-Pierre Golinelli-Cohen, Adriana Zakrzewska and Marc Mirande*}

Laboratoire d'Enzymologie et Biochimie Structurales, UPR 9063 du Centre National de la Recherche Scientifique, 91190 Gif-sur-Yvette, France

\begin{abstract}
Yeast Arc1p, human p43 and plant methionyl-tRNA synthetase (MetRS) possess an EMAPII-like domain capable of non-specific interactions with tRNA. Arc1p interacts with MetRS (MES1) and GluRS and operates as a tRNA-interacting factor (tIF) in trans of these two synthetases. In plant MetRS, the EMAPII-like domain is fused to the catalytic core of the synthetase and acts as a cis-acting tIF for aminoacylation. We observed that the catalytic core of plant MetRS expressed from a centromeric plasmid cannot complement a yeast $a r c 1^{-}$mes $1^{-}$strain. Overexpression of the mutant enzyme from a high-copy number plasmid restored cell growth, suggesting that deletion of its C-terminal tIF domain was responsible for the poor aminoacylation efficiency of that enzyme in vivo. Accordingly, expression of full-size plant MetRS from a centromeric plasmid, but also of fusion proteins between its catalytic core and the EMAPII-like domains of yeast Arc1p or of human p43 restored cell viability. These data showed that homologous tIF domains from different origins are interchangeable and may act indifferently in trans or in cis of the catalytic domain of a synthetase. Unexpectedly, co-expression of Arc1p with the catalytic core of plant MetRS restored cell viability as well, even though Arc1p did not associate with plant MetRS. Because Arc1p also interacts with yeast GluRS, restoration of cell growth could be due at least in part to its role of cofactor for that enzyme. However, co-expression of human p43, a tIF that did not associate with plant MetRS or with yeast GluRS and MetRS, also restored cell viability of a yeast strain that expressed the catalytic core of plant MetRS. These results show that $\mathrm{p} 43$ and Arc1p are able to facilitate tRNA aminoacylation in vivo even if they do not interact physically with the synthetases. We propose that p43/Arc1p may be involved in sequestering tRNAs in the cytoplasm of eukaryotic cells, thereby increasing their availability for protein synthesis.
\end{abstract}

(C) 2004 Elsevier Ltd. All rights reserved.

Keywords: Arc1p; EMAPII; tRNA-interacting factor; methionyl-tRNA synthetase

\section{Introduction}

Present address: A. Zakrzewska, Department of Molecular and Cellular Physiology, University of Cincinnati Medical Center, Cincinnati, OH 45267-0576, USA.

Abbreviations used: MetRS, methionyl-tRNA synthetase; tIF, tRNA-interacting factor; EMAPII, endothelial monocyte-activating polypeptide II; Os, Oriza sativa; Ec, Escherichia coli; Hs, Homeo sapiens; aa, aminoacyl.

E-mail address of the corresponding author: mirande@lebs.cnrs-gif.fr
Aminoacyl-tRNA synthetases catalyze the formation of an ester bond between an amino acid and the $3^{\prime}$ end of a tRNA in a two-step reaction. First, the amino acid is activated and an enzymebound adenylate intermediate is formed. Then, the amino acid is transferred to the $3^{\prime}$ end of the tRNA molecule. ${ }^{1}$ Aminoacyl-tRNA synthetases have to decode the genetic information into amino acids with high fidelity and protein-tRNA 
interactions play a key role in this process. Binding of a tRNA molecule to a synthetase is thought to proceed in two steps: an initial broad-specificity interaction between the tRNA and the synthetase is followed by a more precise recognition that involves conformational changes of both the synthetase and the cognate tRNA ${ }^{2}$ and contributes to tRNA specificity as non-specific tRNAs are normally less efficiently aminoacylated. ${ }^{3}$

Prokaryotic synthetases, which represent the elementary synthetase throughout evolution, are built of two major functional domains constituting the catalytic core: the catalytic domain contains the active site and interacts with the acceptor arm of tRNA; the second domain generally interacts with the anticodon arm. ${ }^{4,5}$ Eukaryotic enzymes present a catalytic core closely related to the respective prokaryotic enzyme, but possess additional domains appended to the $\mathrm{N}$ or C-terminal end. ${ }^{6}$ In higher eukaryotes, polypeptide extensions are hydrophobic and participate in the formation of the multi-synthetase complex, ${ }^{7}$ or are cationic and interact non-specifically with tRNA to improve the catalytic efficiency of the enzyme. According to their primary structures, tRNAinteracting factors (tIF) can be divided into three major families. The first one is found in eukaryotic LysRS, AspRS and AsnRS. ${ }^{8-11}$ A repeated domain is found in human MetRS, HisRS, TrpRS, GlyRS and in the linker region of glutamyl-prolyl-tRNA synthetase. ${ }^{12-15}$ The last type of tIF (EMAPII-like domain) is appended to plant MetRS ${ }^{16}$ or human TyrRS ${ }^{17}$ and acts in cis of the catalytic domain of the synthetase. The EMAPII domain was first identified in human $\mathrm{p} 43$, a non-synthetase protein associated with the multi-synthetase complex, ${ }^{18}$ and is identical with a tumor-derived factor (endothelial monocyte-activating polypeptide II) that alters endothelial functions. ${ }^{19}$ The yeast protein Arc1p (aminoacyl-tRNA synthetase cofactor I), which makes a ternary complex with GluRS and MetRS, possesses a C-terminal domain homologous to EMAPII and acts as a tIF in trans of these two synthetases..$^{20,21}$

Methionyl-tRNA synthetases display an especially variable structural organization throughout evolution. The enzyme can be limited to the catalytic core as in Aquifex aeolicus, or may have an appended C-terminal domain involved in dimer formation as in Escherichia coli.. ${ }^{22,23}$ Plant and human MetRS possess C-terminal extensions with unrelated sequences. In both cases, this domain interacts non-specifically with tRNA, and acts in cis to the catalytic core to improve the catalytic efficiency of the enzyme in the aminoacylation reaction. ${ }^{15,16}$ In yeast, Arc1p possesses a tRNAbinding domain at its C-terminal end. The N-terminal moiety of Arclp interacts with the eukaryotic-specific N-terminal domains of GluRS and MetRS. Association with Arclp provides a tIF in trans to these two enzymes which improves their catalytic efficiency. ${ }^{20,24,25}$ Arc1p is required for optimal growth and is essential for viability of yeast in the absence of the nuclear pore-associated protein Los1p involved in nuclear tRNA export. ${ }^{26}$

Because EMAPII-like domains are found appended to various proteins and are widely distributed among living organisms, we investigated the possibility of rescuing Arclp-deficient yeast cells with fusion proteins containing EMAPII-like domains from different origins. Using MetRS from the rice Oriza sativa (OsMetRS), we showed that in the absence of its C-terminal tIF, the catalytic core of plant MetRS could not complement an arc $1^{-}$ mes $1^{-}$yeast strain. We constructed a series of fusion proteins that tested the capacity of various EMAPII-like domains to act as functional cis-acting tRNA-binding domains in vivo. To further address the function of these EMAPII-like domains, we tested for the absolute requirement of their association in cis or in trans of the synthetases to achieve complementation. Our results establish that human p43 or yeast Arc1p are also able to sustain growth of yeast strains independently of their function of tIF for MetRS and GluRS. These data suggest that in addition to its role of tIF for two synthetases, Arclp may be directly involved in sequestering tRNA in the cytoplasm of yeast.

\section{Results}

\section{OsMetRS can replace ScMetRS in vivo}

Deletion of MES1, the gene coding for ScMetRS, is lethal for yeast, ${ }^{25}$ but deletion of ARC1 only introduces a growth defect. ${ }^{20}$ Expression of Arclp from a centromeric plasmid (pUN100-Arc1) palliates the growth defect of an $\operatorname{arc1} 1^{-}$strain. Arc1p forms a complex with ScMetRS and ScGluRS; ${ }^{20}$ the N-terminal domain of Arclp (Figure 1) interacts with the N-terminal domains of the two synthetases..$^{24,25}$ The C-terminal domain of Arc1p (EMAPII-like domain) binds tRNA and improves the catalytic efficiency of ScMetRS by lowering its $K_{\mathrm{m}}$ value for tRNA ${ }^{\text {Met }}$ in the aminoacylation reaction..$^{20,24}$ These findings suggested that, in yeast, Arc1p operates as a trans-acting tRNA interacting factor (tIF) for two aminoacyltRNA synthetases (GluRS and MetRS).

MetRS from the rice Oriza sativa (OsMetRS) can be divided into three distinct domains (Figure 1): the catalytic core at the N-terminal end with high sequence similarity with prokaryotic MetRS (50\% identities); an EMAPII-like domain at the C-terminal end (53\% identities with the C-terminal domain of Arc1p); and a median (M) domain with no sequence similarity with any known protein. ${ }^{27}$ In vitro, the $(\mathrm{M}+\mathrm{C})$ domain of OsMetRS clearly provides tRNA-binding properties to the native enzyme and acts as a cis-acting tIF for aminoacylation. ${ }^{16}$ We tested whether OsMetRS or its isolated catalytic domain obtained after deletion of the $(\mathrm{M}+\mathrm{C})$ domain could rescue an $\operatorname{arcl}^{-}$ mes1- yeast strain. For the clarity of this paper, we will name arc1 $^{-}$mes1 $1^{-}$(protein A, protein B, etc.) 


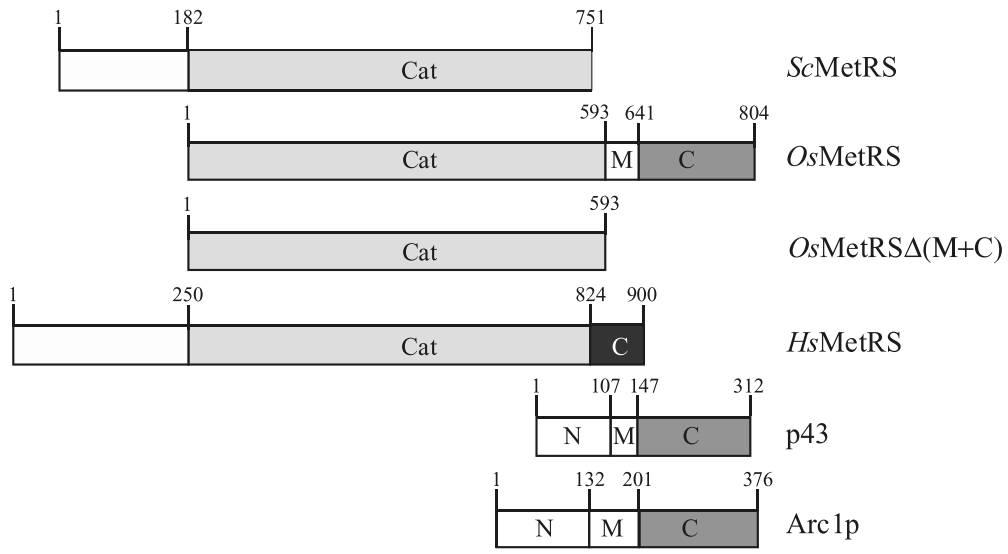

Figure 1. Schematic representation of the sequences of MetRSs from S. cerevisiae (ScMetRS), O. sativa (OsMetRS) or H. sapiens (HsMetRS), of H. sapiens p43 (p43) and of S. cerevisiae Arc1p (Arc1p). A light grey bar represents the catalytic core of the different MetRSs. A black bar represents the C-terminal extension of HsMetRS. Grey bars represent EMAPII-like domains at the C-terminal end of OsMetRS, Arc1p and p43. the yeast strain with gene disruptions of $A R C 1$ and MES1 transformed with the plasmids expressing protein $\mathrm{A}$, protein $\mathrm{B}$, etc. Thus, the $\operatorname{arc} 1^{-}$mes1 strain transformed with the centromeric plasmid expressing ScMetRS will be noted $\operatorname{arc1}^{-}$mes1 (ScMetRS). If a $2 \mu$ plasmid is used, then the notation will be arc1 ${ }^{-}$mes1 $^{-}(S c M e t R S / 2 \mu)$.

A arc1 $^{-}$mes1 $^{-}$(ScMetRS) strain expressing ScMetRS from a centromeric plasmid containing $U R A 3$ was transformed with a second centromeric plasmid containing TRP1 and expressing OsMetRS. After overnight culture in the presence of uracil, cells were plated on a growth medium containing 5'-fluoroorotic acid (FOA), which achieves the counter selection of cells containing
URA3 plasmids. This complementation assay showed that expression of OsMetRS restored cell viability (Figure 2A).

Previous in vitro studies have shown that deletion of the $\mathrm{M}$ and C-terminal domains of OsMetRS produces a stable monomeric enzyme with a tenfold decrease in $K_{\mathrm{m}}$ for tRNA in the aminoacylation reaction. ${ }^{16}$ When this MetRS species, OsMetRS $\Delta(M+C)$, was expressed from a centromeric plasmid, cell viability was not restored (Figure 2A). Thus, deletion of the $(\mathrm{M}+\mathrm{C})$ domain of OsMetRS also impairs the catalytic efficiency of the enzyme in vivo. However, when OsMetRS $\Delta(\mathrm{M}+\mathrm{C})$ was expressed from a multicopy plasmid, cell viability was restored

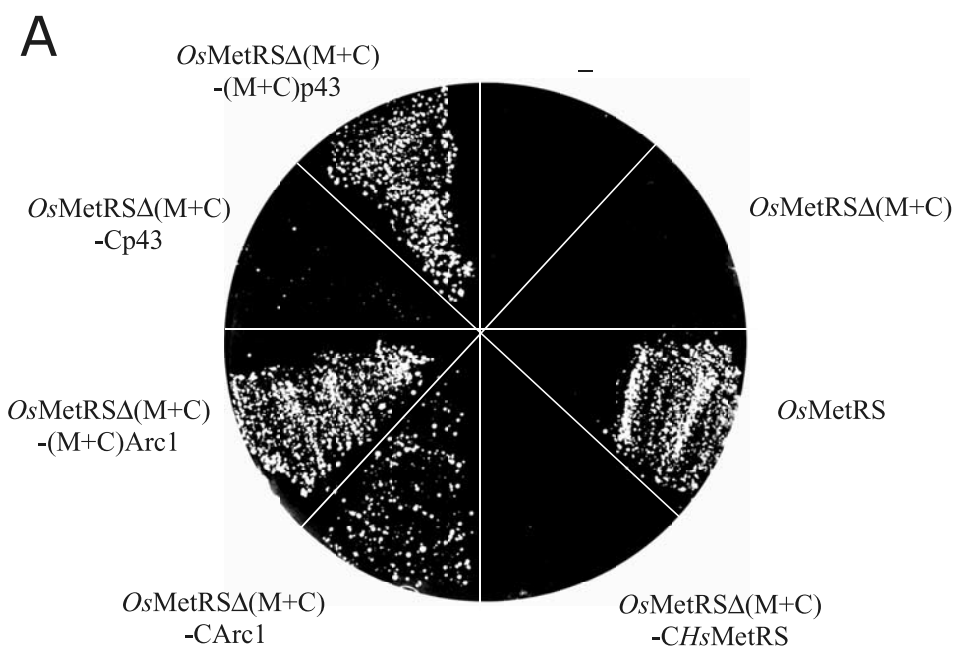

B

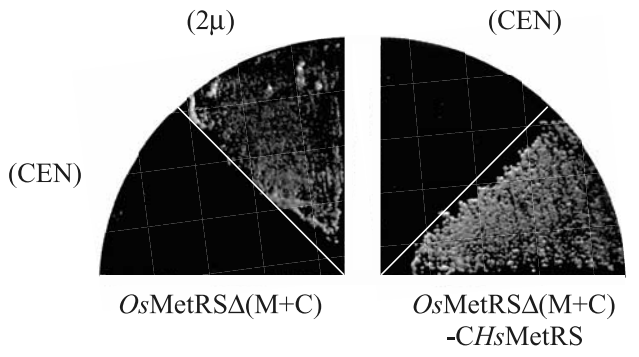

Figure 2. OsMetRS and fusion proteins derived from OsMetRS can replace ScMetRS in yeast. A, arc1 $^{-}$mes1- $^{-}$(ScMetRS) strain was transformed by centromeric plasmids expressing OsMetRS or a fusion protein derived from OsMetRS and complementation experiments were performed as described in Materials and Methods. Plates were incubated for four days at $28^{\circ} \mathrm{C}$. B, $\operatorname{arcl}^{-}$ mes1 $1^{-}$(ScMetRS) strain was transformed by centromeric (CEN) or multicopy $(2 \mu)$ plasmids expressing OsMetRS $\Delta(\mathrm{M}+\mathrm{C})$ and OsMetRS $\Delta(\mathrm{M}+\mathrm{C})-\mathrm{CHsMetRS}$ and tests of complementation were conducted. Plates shown in A and B are representative of at least three independent experiments. 
(Figure 2B). This result suggests that increasing the expression level of the catalytic core of OsMetRS could palliate its poor aminoacylation efficiency.

\section{The C-terminal domain of OsMetRS can be replaced by other tRNA-binding domains}

p43 is one of the three auxiliary proteins associated with nine aminoacyl-tRNA synthetases in a multi-enzyme complex ubiquitous to higher eukaryotes. $^{28}$ As Arc1p, p43 can be devided into three distinct domains (Figure 1). The C-terminal domains of both yeast Arc1p and human p43 are capable of binding tRNA. In both cases, the affinity of the C-terminal domain of the protein for tRNA is improved in the presence of the M domain. ${ }^{18,20,24}$ Like OsMetRS, human MetRS (HsMetRS) possesses a C-terminal domain capable of binding tRNA (Figure 1). ${ }^{15}$ However, no sequence similarity exists between the $(\mathrm{M}+\mathrm{C})$ domain of OsMetRS and the C-terminal domain of HsMetRS; the EMAPII-like domain of OsMetRS has an OB-fold conformation whereas the C-terminal domain of HsMetRS corresponds to a helix-turn-helix motif. ${ }^{12,29} \mathrm{We}$ expressed chimeric proteins made of the catalytic core of OsMetRS (OsMetRS $\Delta(\mathrm{M}+\mathrm{C})$ ) and of C-terminal fragments of yeast Arc1p, human p43 or HsMetRS capable of binding tRNA, and we tested the activity of the fusion proteins in an in vivo complementation assay.

Five different fusion proteins were expressed. OsMetRS $\Delta(\mathrm{M}+\mathrm{C})$-CArc1 and OsMetRS $\Delta(\mathrm{M}+\mathrm{C})$ Cp43 containing the $\mathrm{C}$-terminal domain of yeast Arc1p and human p43, respectively, could clearly complement an arcl $^{-}$mes1 $1^{-}$strain (Figure 2A). The efficiency of complementation was correlated with the tRNA-binding potency of the domain fused to OsMetRS $\Delta(\mathrm{M}+\mathrm{C})$. Indeed, complementation was clearly improved when the $\mathrm{M}$ domain of Arc1p or of p43 was also present $(O s M e t R S \Delta(M+$ $\mathrm{C})-(\mathrm{M}+\mathrm{C}) \mathrm{Arc1}$ and $\operatorname{OsMetRS} \Delta(\mathrm{M}+\mathrm{C})-(\mathrm{M}+$ C)p43, respectively) (Figure 2A). Thus, addition of a tRNA-binding domain to the catalytic core of OsMetRS restored cell viability. However, when the C-terminal domain of HsMetRS was fused to the catalytic core of rice MetRS (OsMetRS $\Delta(\mathrm{M}+$ C)-CHsMetRS (Figure 2A)), only few cells grew in the complementation assay. This could be due to the tRNA-sequestering function of this domain ${ }^{15}$ that might impair the rate of Met-tRNA ${ }^{\text {Met }}$ release in vivo. As for OsMetRS $\Delta(\mathrm{M}+\mathrm{C})$, expression of OsMetRS $\Delta(\mathrm{M}+\mathrm{C})$-CHsMetRS using a multicopy plasmid improved the ability of the fusion protein to complement the $\operatorname{arc1} 1^{-}$mes1 ${ }^{-}$strain (Figure 2B).

These results are consistent with the interpretation according to which EMAPII-like tRNA-binding domains are functional cis-acting tIFs for the catalytic core of OsMetRS, improve the efficiency of tRNA aminoacylation in vivo and, consequently, restore cell viability. These results also showed that the $(\mathrm{M}+\mathrm{C})$ domain of human $\mathrm{p} 43$, the human homolog of yeast Arc1p, can fulfill the role of tIF in cis to the catalytic core of a synthetase.

Yeast strains $\operatorname{arcl}^{-}$mes1 ${ }^{-}$rescued by ScMetRS, OsMetRS, OsMetRS $\Delta(\mathrm{M}+\mathrm{C})-(\mathrm{M}+\mathrm{C}) \mathrm{Arc1}$, and OsMetRS $\Delta(\mathrm{M}+\mathrm{C})-(\mathrm{M}+\mathrm{C}) \mathrm{p} 43$ grew at similar rates on rich medium (Table 1 and Figure 3 ). A growth rate identical with that of the $\mathrm{arcl}^{-}$mes1 (ScMetRS, Arc1p) strain was never reached, indicating that the presence of a tIF domain acting in cis of MetRS cannot completely palliate the growth defect of the $\operatorname{arc1} 1^{-}$mes1 $1^{-}$strain. This result is consistent with the finding that Arclp acts in trans of MetRS but also of GluRS. ${ }^{20}$ Therefore, rescuing the

Table 1. Doubling-times $(\tau)$ at 20,28 , and $37^{\circ} \mathrm{C}$ of $\operatorname{arc} 1^{-}$mes $1^{-}$strains expressing yeast MetRS (ScMetRS), rice MetRS (OsMetRS) or a fusion protein derived from rice MetRS, with or without co-expression of an auxiliary protein

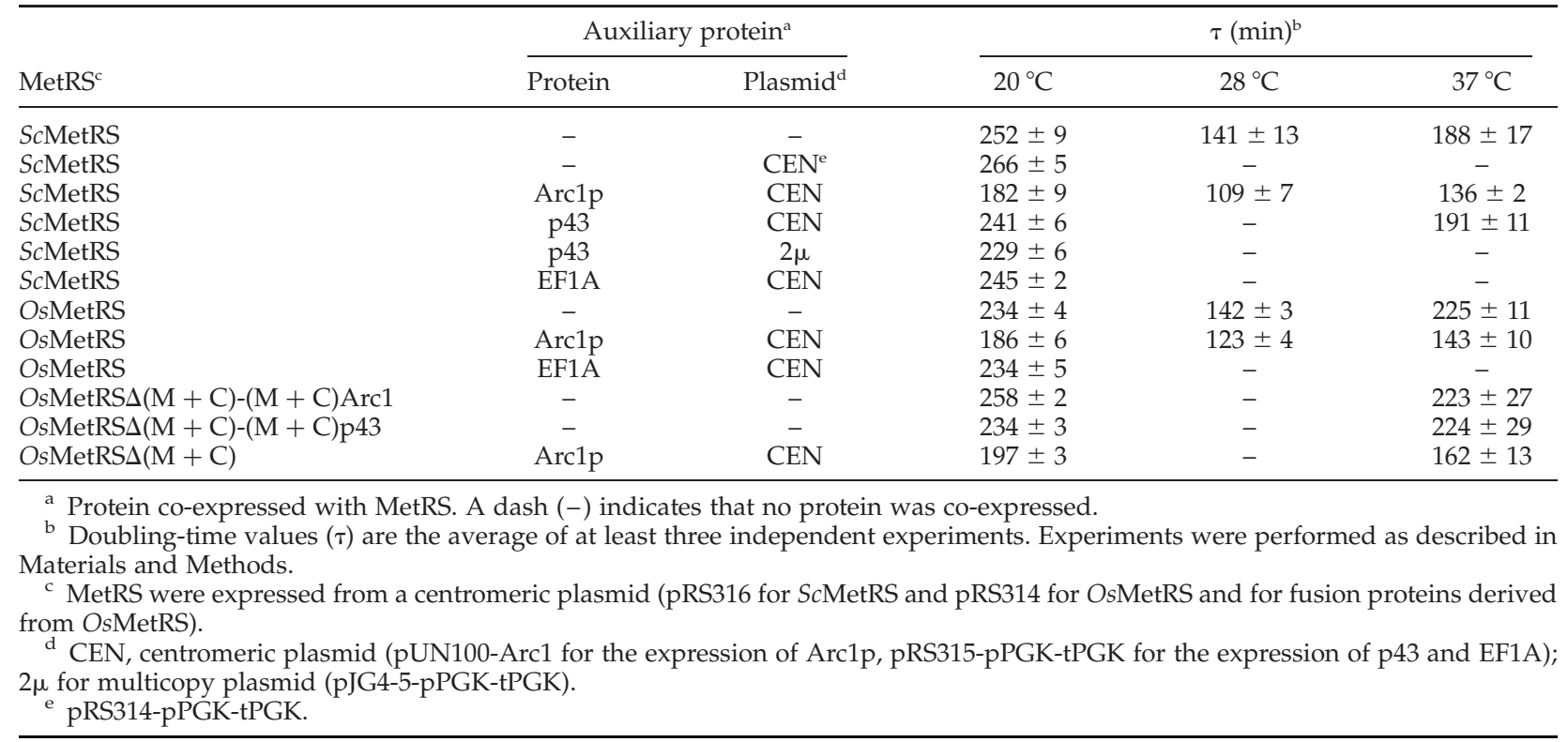




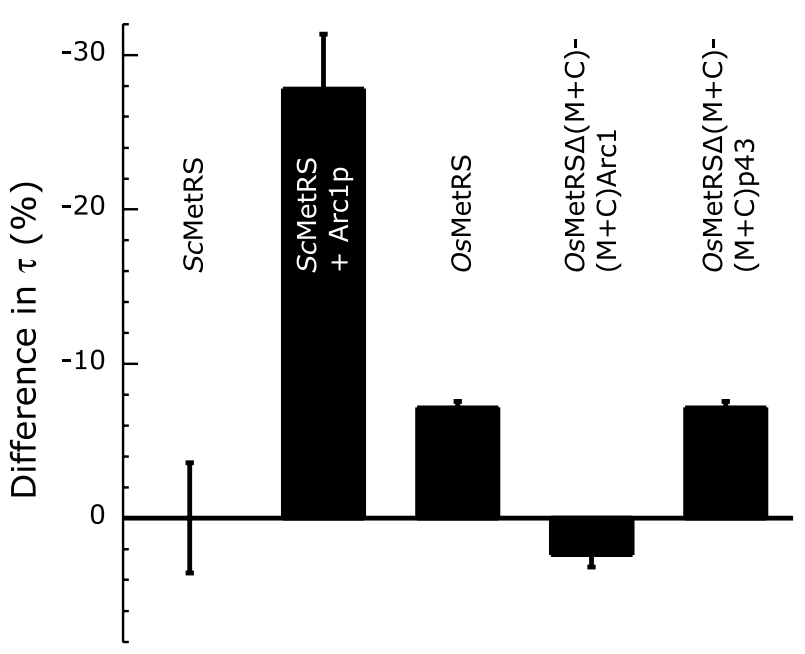

Figure 3. Comparison of the growth rates of $\operatorname{arcl}^{-}$ mes $1^{-}$strains rescued by different MetRS species. Differences between growth rates at $20^{\circ} \mathrm{C}$ are expressed by the difference between the doubling-time $(\tau)$ of the strain and the $\tau$ value of $\mathrm{arc1}^{-}$mes1 ${ }^{-}$(ScMetRS) strain $(\tau=252( \pm 9)$ minutes $)$ and are the average of at least three independent experiments. The different MetRSs (as indicated) and Arc1p are expressed from centromeric plasmids.

activity of MetRS alone is not sufficient to restore a wild-type phenotype.

\section{Arc1p stimulates growth of arc1 $^{-}$mes1- cells expressing OsMetRS or a fusion protein thereof}

As shown, ${ }^{20}$ the growth defect phenotype of $\mathrm{arc1}^{-}$mes1 $^{-}$(ScMetRS) can be palliated by coexpression of Arc1p from a centromeric plasmid (strain $\operatorname{arc1}^{-}$mes1 $^{-}$(ScMetRS, Arc1p)). Expression of Arc1p in trans of ScMetRS significantly improved the growth rate of the strain in solid (Figure 4A) and liquid media (Table 1). Effects were larger at non-optimal temperatures (at $20^{\circ} \mathrm{C}$ or $37^{\circ} \mathrm{C}$, the doubling-time of the strain, $\tau$, was improved by $30 \%$ ) than at physiological growth temperature (a $20 \%$ improvement of $\tau$ at $28^{\circ} \mathrm{C}$ ). When cells were transformed with a control plasmid (pRS314-pPGK-tPGK) or with a plasmid expressing an unrelated human protein (pRS315EF1A), the growth rate was not significantly affected (Table 1).

Similarly, co-expression of Arc1p with OsMetRS (Figure 4B and Table 1) or with fusion proteins containing the catalytic core of OsMetRS fused to EMAPII-like tIFs (Figure 4C) also improved cell growth. Because Arc1p cannot interact with OsMetRS (see below), these data are consistent with the function of tIF acting in trans of yeast GluRS attributed to Arc1p. Thus, restoration of a wild-type growth phenotype is likely to require that both MetRS and GluRS are functionally linked to tIFs that may be associated in cis or in trans of their catalytic core.
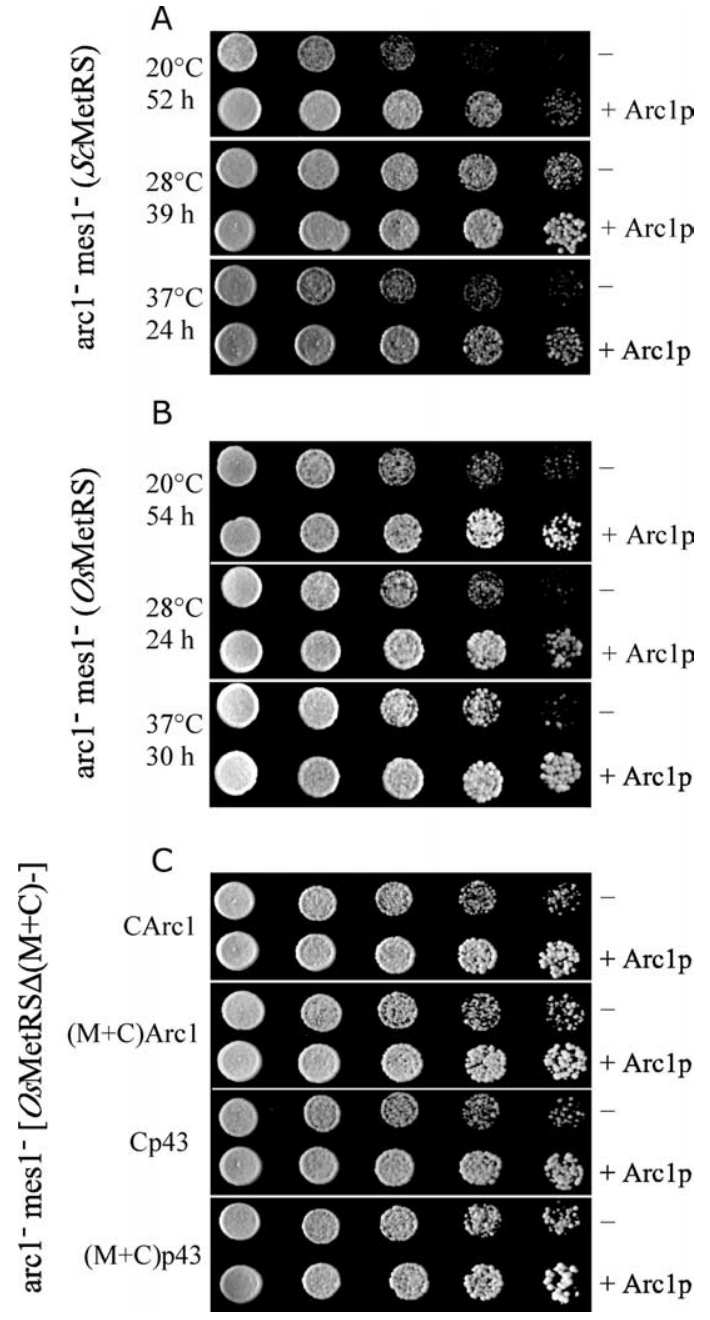

Figure 4. Arc1p can palliate the growth defect of arc1 mes $1^{-}$strains expressing ScMetRS, OsMetRS or a fusion protein derived from OsMetRS. Cells transformed by centromeric plasmids were grown in minimal medium, serially diluted, and aliquots were spotted onto YPG plates containing adenine and tryptophan, when necessary. Where indicated, yeast cells also expressed Arc1p from pUN100-Arc1. A, arc1 ${ }^{-}$mes1- (ScMetRS) strain. B, $\operatorname{arc}^{-}$mes1 $^{-}$(OsMetRS) strain. Plates were incubated at the temperatures and for the times indicated. C, arc1 ${ }^{-}$ mes $1^{-}$strains expressing fusion proteins derived from OsMetRS $\Delta(\mathrm{M}+\mathrm{C})$. Cells were incubated at $37^{\circ} \mathrm{C}$ for 35 hours. Plates are representative of at least two independent experiments.

\section{Arc1p can restore cell viability of a yeast strain with a defective MetRS}

The weak in vivo aminoacylation efficiency of the catalytic core of rice MetRS can be palliated by its overexpression (Figure 2B) or by fusion of a tIF domain (Figure 2A). Surprisingly, co-expression of Arc1p with OsMetRS $\Delta(\mathrm{M}+\mathrm{C})$ also restored viability of arc $^{-}$mes1 $^{-}$cells (Figure 5). This result was unexpected, since Arc1p was not supposed to interact with the catalytic core of rice MetRS. Indeed, Arc1p operates as a trans-acting tIF for 


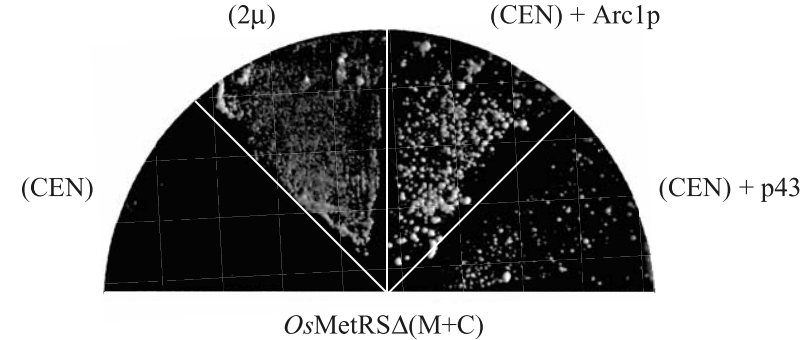

Figure 5. Ability of Arc1p and p43 to rescue arc1 mes1 ${ }^{-}$cells expressing OsMetRS $\Delta(\mathrm{M}+\mathrm{C})$. A $\operatorname{arc1}^{-}$ mes1 $^{-}$(ScMetRS) strain was transformed with a centromeric (CEN) or multicopy $(2 \mu)$ plasmid expressing $\operatorname{OsMetRS} \Delta(\mathrm{M}+\mathrm{C})$ and, where indicated, with a centromeric plasmid expressing Arc1p or p43. Tests of complementation were performed at $28{ }^{\circ} \mathrm{C}$ for four days. This plate is representative of at least three independent experiments.

ScMetRS by interacting with tRNA via its C-terminal domain and with ScMetRS via its N-terminal domain..$^{20,24,25}$ Outside the catalytic core, OsMetRS has no similarity of sequence with ScMetRS; especially OsMetRS does not have a polypeptide extension similar to that found at the $\mathrm{N}$-terminal end of ScMetRS and responsible for its interaction with Arc1p. ${ }^{24,25}$ Thus, we did not expect that OsMetRS could interact with Arc1p.

We first sought to verify that Arc1p does not form a complex with OsMetRS. To find out whether Arc1p associates physically with OsMetRS, Arc1p was affinity-purified as an epitope-tagged fusion protein containing the IgGbinding domain derived from Staphylococcus aureus protein A (ProtA-Arc1p). ProtA-Arc1p was functional as well as Arc1p. ${ }^{20}$ As a control, IgGSepharose was incubated with a soluble extract of arc1 $^{-}$mes1 $^{-}$(ScMetRS, ProtA-Arc1p) strain. As expected, analysis by Western blotting using antibodies directed to ScMetRS or ScGluRS showed that both synthetases co-purified with ProtAArc1p (Figure 6). A similar experiment was performed with $\operatorname{arc1}^{-}$mes1 $^{-}$(OsMetRS $\Delta(\mathrm{M}+\mathrm{C})$ $(\mathrm{M}+\mathrm{C}) \mathrm{p} 43$, ProtA-Arc1p) extract. Using antibodies raised against the C-terminal domain of p43, we found that OsMetRS $\Delta(M+C)$ $(\mathrm{M}+\mathrm{C}) \mathrm{p} 43$ was not co-purified with ProtA-Arc1p (Figure 6). Thus, Arc1p does not interact with the catalytic core of OsMetRS as it does with the N-terminal domain of ScMetRS. Therefore, in the absence of protein-protein interaction, Arc1p cannot act as a tIF in trans of $\operatorname{OsMetRS} \Delta(\mathrm{M}+\mathrm{C})$.

The restoration of viability of $\mathrm{arc}^{-}$mes1 $(O s M e t R S \Delta(M+C))$ following co-expression of Arc1p suggested that MetRS activity is not the limiting factor for growth of $\operatorname{arcl}^{-}$strains. Moreover, the growth rate of the resulting strain $\operatorname{arcl}^{-}$ mes1 ${ }^{-}(O s M e t R S \Delta(M+C)$, Arc1p) was very similar to that of $\mathrm{arc1}^{-}$mes1- (OsMetRS, Arc1p), or even to that of $\operatorname{arc1}^{-}$mes1 $1^{-}$(ScMetRS, Arc1p) corresponding to wild-type (Figure 7 and Table 1).

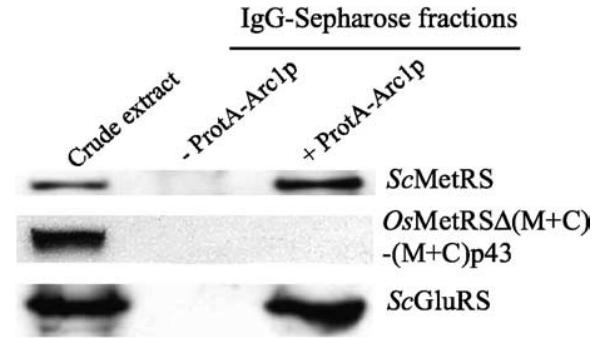

Figure 6. Arc1p does not interact with the catalytic domain of OsMetRS. ProtA-Arc1p from arc1- mes1cells co-transformed with plasmids that expressed ScMetRS or OsMetRS $\Delta(\mathrm{M}+\mathrm{C})-(\mathrm{M}+\mathrm{C}) \mathrm{p} 43$ was affinitypurified on IgG-Sepharose. Proteins absorbed on IgG-Sepharose were analyzed by Western blotting with antibodies directed to ScMetRS, p43 or ScGluRS. The corresponding crude extracts were analyzed in parallel. Negative controls were performed with crude extracts of cells that did not express ProtA-Arc1p.

Thus, because Arc1p does not associate with rice MetRS, these data suggested that the main consequence of the lack of Arc1p would be to lower the catalytic efficiency of GluRS. Alternatively, another not yet defined function of Arc1p could be the primary defect of strains with a null-allele of ARC1.

\section{Human p43 can restore Arc1p}

Because $\mathrm{p} 43$, the human homolog of yeast Arc1p, was not supposed to form a complex with either yeast MetRS and GluRS or with rice MetRS, we anticipated that it might be a good tool to test for the absolute requirement of a tIF acting in cis or in trans of MetRS or GluRS to rescue $\operatorname{arc1} 1^{-}$strains. As shown above with Arc1p, co-expression of human p43 with the catalytic core of OsMetRS also restored viability of $\operatorname{arcl}^{-}$mes $^{-}$cells (Figure 5). The growth rate of this strain ( $\tau$ at $20{ }^{\circ} \mathrm{C}$ of $249( \pm 4)$ minutes) was similar to that of $\operatorname{arc}^{-}$mes1 $^{-}$(ScMetRS) $\left(\tau\right.$ at $20^{\circ} \mathrm{C}$ of $252( \pm 9)$ minutes) (Table 1).

As Arc1p, p43 possesses an EMAPII domain capable of non-specific interaction with tRNA. ${ }^{18}$ Its $\mathrm{N}$-terminal end is involved in dimerization of the protein $^{30}$ and interacts with ArgRS and p38, two other components of the mammalian multi-synthetase complex. ${ }^{31}$ Except for the C-terminal domain, p43 has no significant similarity of sequence with Arc1p and we hypothesized that human p43 does not interact with ScMetRS, ScGluRS, or OsMetRS. To look for a possible interaction between human p43 and ScMetRS, ScGluRS or OsMetRS, Histagged p43 protein was incubated with cell extracts from yeast containing ScMetRS and ScGluRS (arc1 ${ }^{-}$ mes1 $\left.{ }^{-}(S c M e t R S)\right)$ or OsMetRS $\Delta(\mathrm{M}+\mathrm{C})-(\mathrm{M}+$ C)p43 (arc1 ${ }^{-}$mes1 $^{-} \quad(O s M e t R S \Delta(M+C)-(M+$ C)p43)). Using affinity-purified antibodies directed to the His-tag, we observed that ScMetRS, ScGluRS and OsMetRS $\Delta(\mathrm{M}+\mathrm{C})-(\mathrm{M}+\mathrm{C}) \mathrm{p} 43$ were not co-immunoprecipitated with His-tagged p43 


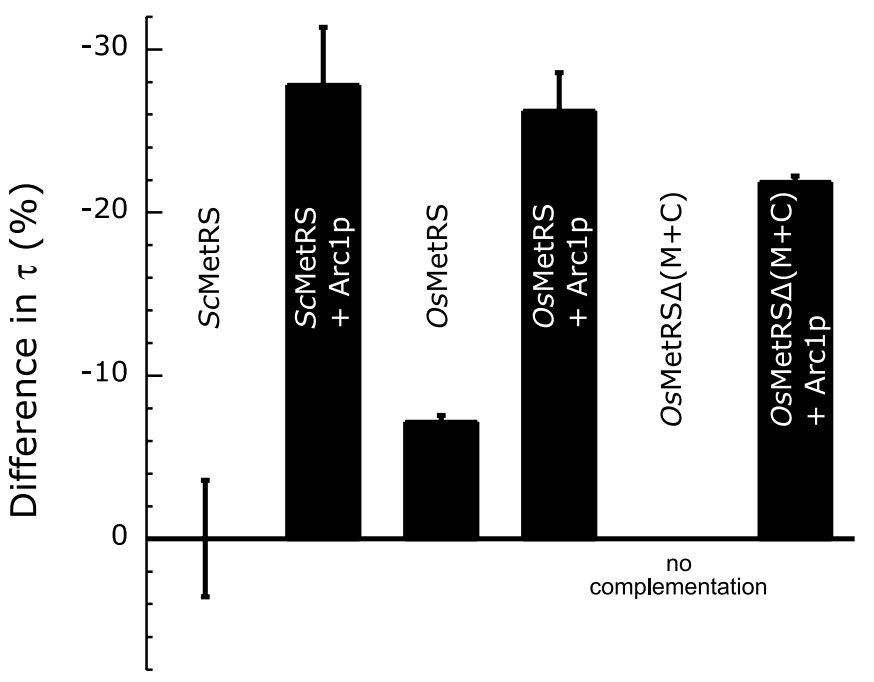

Figure 7. Expression of Arc1p stimulates growth rates of $\operatorname{arc1}$ mes $1^{-}$strains rescued by different MetRS species. Differences between growth rates at $20{ }^{\circ} \mathrm{C}$ are expressed as for Figure 3 and are the average of at least three independent experiments. The different MetRSs (as indicated) and Arc1p are expressed from centromeric plasmids.

(Figure 8A). In a control experiment, mammalian ArgRS that interacts with $\mathrm{p} 43^{31}$ was recovered within the immunoprecipitate (Figure 8A). By immunoprecipitation and Western blot, we were able to show the interaction between ArgRS and p43, two proteins that associate with an apparent dissociation constant $K_{\mathrm{d}}$ value of $93 \mathrm{nM}^{31}$ but not between p43 and ScMetRS, ScGluRS or OsMetRS. Due to the sensitivity of this assay, we might expect to demonstrate the formation of a complex with a $K_{\mathrm{d}}$ value up to 5-10 $\mu \mathrm{M}$. Thus, p43 cannot associate with ScMetRS, ScGluRS or OsMetRS at protein concentrations prevailing in vivo and, consequently, p43 cannot act as a tIF in trans of these enzymes.

As an additional control experiment, we also examined the possibility that p43 only transiently associates with OsMetRS $\Delta(\mathrm{M}+\mathrm{C})$ but may still stimulate its activity. The time course of tRNA ${ }^{\text {Met }}$ aminoacylation catalyzed by $\operatorname{OsMetRS} \Delta(\mathrm{M}+\mathrm{C})$ was followed in the absence or in the presence of one or ten molar excess of p43 in the assay, under conditions where tRNA was not saturating (Figure $8 \mathrm{~B}$ ). The $\mathrm{tRNA}^{\mathrm{Met}}$ aminoacylation capacity of the enzyme was not affected by addition of $\mathrm{p} 43$ in the assay. These results show that human p43 interacts neither physically nor functionally with the catalytic core of rice MetRS.

\section{Expression of human p43 improves growth of arc1- $^{-}$cells}

If p43 is able to replace Arc1p in a MetRS and GluRS-independent pathway, it should be able to rescue the growth defect phenotype of the arc $1^{-}$ mes1 $^{-}$(ScMetRS) strain. Expression of human p43 from a centromeric plasmid did only slightly affect the growth rate of the strain (Figure 9A). Interestingly, expression of p43 from a multicopy plasmid significantly improved the growth of arc1 $1^{-}$mes1 $1^{-}$ (ScMetRS) (Figure 9A and Table 1).

Similarly, p43 may also rescue a $\operatorname{los} 1^{-} \operatorname{arc1}^{-}$
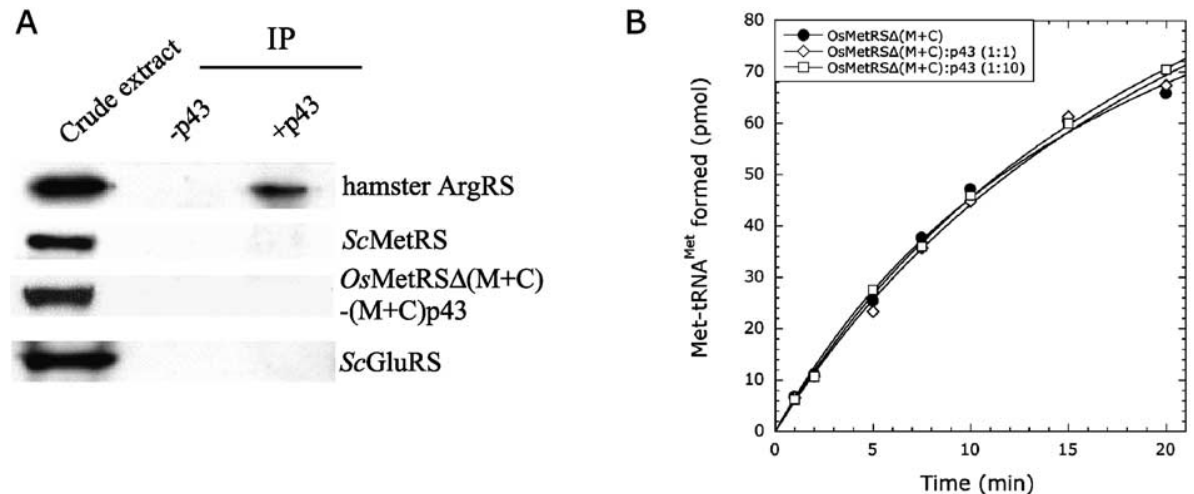

Figure 8. p43 does not interact with ScMetRS, OsMetRS or ScGluRS and does not interfere with OsMetRS activity. A, Cell extracts of strain W303-1B expressing hamster ArgRS, of strain arc1 ${ }^{-}$mes1 $1^{-}$expressing ScMetRS and ScGluRS, or of strain $\operatorname{arc1}^{-}$mes1- expressing OsMetRS $(\mathrm{M}+\mathrm{C})-(\mathrm{M}+\mathrm{C}) \mathrm{p} 43$ were incubated with His-tagged human p43 or not (negative control). Immunoprecipitates (IP) obtained with anti-(His-tag) antibodies were analyzed by Western blotting with antibodies directed to hamster ArgRS, ScMetRS, p43 or ScGluRS. The corresponding crude extracts were analyzed in parallel. B, The activity of $\operatorname{OsMetRS} \Delta(\mathrm{M}+\mathrm{C})$ was determined in the tRNA ${ }^{\mathrm{Met}}$ aminoacylation reaction in the presence or in the absence of p43, as described in Materials and Methods. 
A

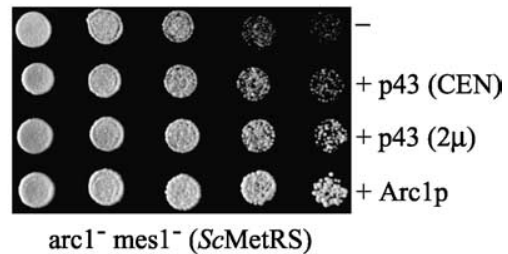

B

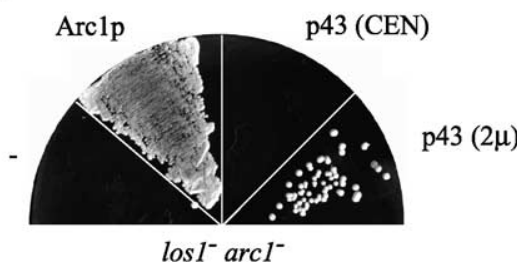

Figure 9. $\mathrm{p} 43$ palliates the growth defect of an arc1 mes1 $1^{-}$(ScMetRS) strain and rescues a los $1^{-}$arc $1^{-}$strain. A, arc1 ${ }^{-}$mes1 $^{-}$(ScMetRS) cells co-transformed with a centromeric $(\mathrm{CEN})$ or multicopy $(2 \mu)$ plasmid expressing human $\mathrm{p} 43$ or with a centromeric plasmid expressing Arc1p were grown in minimal medium, serially diluted, and spotted onto YPG plates. The plate was incubated 68 hours at $20^{\circ} \mathrm{C}$. B, los $1^{-}$arc $1^{-}$strain was transformed with plasmids expressing human p43 (centromeric (CEN) or multicopy $(2 \mu)$ ) or yeast Arc1p (centromeric) and tests of complementation were conducted. The plate shown in B was incubated for six days at $28^{\circ} \mathrm{C}$ and is representative of at least three independent experiments.

strain. Yeast Los1p is involved in tRNA export from the nucleus to the cytoplasm. ${ }^{32,33}$ Disruption of LOS1 does not cause any apparent growth defect, suggesting that export of tRNA still continues in the absence of Los1p at least to an extent that supports normal cell growth. ${ }^{32}$ When the single deletion of chromosomal ARC1 or LOS1 is not lethal for yeast, the double deletion is lethal. This synthetic lethality suggested the involvement of Arc1p in tRNA export or, more generally, in the cytoplasmic localization of tRNA. ${ }^{26}$ As shown, expression of Arc1p restored cell viability ${ }^{26}$ (Figure 9B). Expression of human p43 from a centromeric plasmid could not rescue a $\operatorname{los} 1^{-}$ arc1 $^{-}$strain, but its expression from a $2 \mu$ plasmid achieved the complementation (Figure 9B).

Thus, even if p43 cannot interact with yeast MetRS and GluRS, its expression improves the growth rate of cells lacking Arc1p. All these findings suggest that Arc1p is involved in a cellular pathway independent of its ability to associate with MetRS and GluRS, and that p43 may also fulfill this function in vivo.

\section{Discussion}

Arc1p forms a ternary complex with ScMetRS and ScGluRS and acts as a tIF in trans of both synthetases to improve their catalytic efficiencies. ${ }^{20,24}$ The human homolog of Arc1p, the p43 protein, is associated within a multi-enzyme complex containing nine aminoacyl-tRNA synthetases and two other non-synthetase proteins. ${ }^{18}$ Yeast Arc1p, human p43 as well as rice MetRS (OsMetRS) possess EMAPII-like C-terminal domains. ${ }^{16,18,20}$ In vitro, the EMAPII-like domain of OsMetRS interacts non-specifically with tRNA, decreases the $K_{\mathrm{m}}$ value of the enzyme for tRNA ${ }^{\mathrm{Met}}$, improves the catalytic efficiency of MetRS at the non-saturating tRNA concentrations that prevail in vivo but does not significantly affect its $k_{\text {cat }}$ value. ${ }^{16}$ The EMAPII-like domain of OsMetRS acts as a tIF in cis of the catalytic core of the enzyme (OsMetRS $\Delta(\mathrm{M}+\mathrm{C})$, with our notation). Whereas the tRNA-binding capacity of the EMAPII domain of human p43 has been clearly shown in vitro, ${ }^{18,30}$ its possible involvement in vivo as a tIF in trans of an aminoacyl-tRNA synthetase was not demonstrated. The results reported here reveal that the EMAPII-like domain of OsMetRS and the EMAPII domain of human p43 have the potential to act as functional tIFs in vivo and put new perspectives on the role of Arc1p in yeast.

\section{EMAPII-like domains are functional tIFs for aminoacyl-tRNA synthetases}

Our results clearly showed that the EMAPII-like domains of yeast Arc1p and of human p43 can act as tIFs in cis when fused to the catalytic core of a synthetase. Fusion proteins containing the $\mathrm{C}$ or the $(\mathrm{M}+\mathrm{C})$ domain from Arc1p or from $\mathrm{p} 43$ fused to the C-terminal end of the catalytic core of OsMetRS expressed from a low copy number plasmid restored viability of $\operatorname{arc} 1^{-}$mes1 $1^{-}$cells. Similarly, addition of the N-terminal tRNA-binding domain of yeast glutaminyl-tRNA synthetase or of the $C$ or the $(M+C)$ domain of Arclp to the $\mathrm{C}$ terminus of E. coli AlaRS or to the $\mathrm{N}$ terminus of E. coli GlnRS converted them into functional yeast enzymes in vivo and in vitro. ${ }^{34-36}$ In these studies, expression of E.coli GlnRS from a high copy number plasmid did not complement the yeast knockout. ${ }^{37}$ Here, we show that the catalytic core of OsMetRS can complement the $\operatorname{arc1} 1^{-}$mes1 ${ }^{-}$strain when expressed from a high copy number plasmid. These results indicate that the catalytic core of OsMetRS alone is able to form a productive complex with yeast tRNA ${ }^{\text {Met }}$, but its low affinity for tRNA has to be compensated for by an increase of its in vivo concentration to restore cell viability. Thus, an efficient synthetase-tRNA complex can be restored in vivo either by increasing the cellular concentration of the enzyme or by enhancing its affinity for yeast tRNA (addition of a cis-acting tIF to the catalytic core).

The polybasic M-domain of Arc1p or of p43 improves the affinity of the EMAPII-like domain for tRNA in vitro ${ }^{20,24}$ (V. Shalak \& M.M., unpublished results). In our experiments, the efficiency of complementation of arc1- mes1- cells was clearly correlated with the affinity for tRNA of the domain fused to the catalytic core of OsMetRS: the 
$(\mathrm{M}+\mathrm{C})$ domains of Arc1p and p43 proved to be more effective than the corresponding $\mathrm{C}$ domains. These results are consistent with the interpretation according to which the major effect of the fusion of a non-specific RNA binding domain to the catalytic core of an eukaryotic synthetase is to lower the $K_{d}$ value of the enzyme for tRNA.

Remarkably, the same tIF may act in trans (Arc1p with ScMetRS) or in cis (C-Arc1p with the catalytic domains of OsMetRS, EcAlaRS or EcGlnRS) of a synthetase and, in the latter case, may be appended at the $\mathrm{N}$ (C-Arclp with the catalytic domain of $E c G \ln R S)$ or at the C (C-Arc1p with the catalytic domains of OsMetRS or EcAlaRS) terminus of the catalytic core of a synthetase. All these data suggest that the peptide segment that links the catalytic domain of the synthetase and the tIF is flexible enough to contribute a productive interaction with the tRNA molecule, irrespective of the polarity of the fusion and to accommodate the different tRNA-binding modes of class-I (MetRS and GlnRS) and class-II (AlaRS) aminoacyl-tRNA synthetases.

\section{Dual function of Arc1p/p43}

Strikingly, co-expression of human p43 also rescued the $\operatorname{arcl}^{-}$mes $^{-}$strain that expressed the catalytic core of rice MetRS from a low copy number plasmid. Because p43 does not form a complex with OsMetRS or with yeast GluRS, p43 could not act as a tIF in trans of either of these two enzymes. Moreover, expression of p43 in $\operatorname{arcl}^{-}$mes $^{-}$ (ScMetRS) also improved the growth rate of the cells even though p43 does not interact with ScMetRS and ScGluRS. Similarly, Arclp also rescued the $\operatorname{arcl}^{-}$mes1- ${ }^{-}$(OsMetRS $\left.\Delta(\mathrm{M}+\mathrm{C})\right)$ strain. The N-terminal domain of Arc1p interacts with the N-terminal domain of ScMetRS but also with the N-terminal domain of ScGluRS. ${ }^{25}$ OsMetRS does not possess a domain similar to the N-terminal extension of ScMetRS and has no similarity of sequence with ScMetRS outside the catalytic core. The complex between ScMetRS and Arclp can be easily isolated from cell extracts of yeast but formation of a similar complex between Arc1p and OsMetRS was not observed. However, because Arc1p also associates with yeast GluRS and provides GluRS with enhanced tRNA binding capacities, complementation of $\operatorname{arcl}^{-}$mes1 $^{-}$ $(O s \operatorname{MetRS} \Delta(\mathrm{M}+\mathrm{C}))$ with Arc1p might be attributed to its trans-acting effect on GluRS. Thus, in the yeast system, the involvement of Arc1p in a MetRS and GluRS-independent pathway might have been observed only in a double mutant strain carrying deletions of the N-terminal domains of both MetRS and GluRS.

Human p43 also rescued a $\operatorname{los} 1^{-} \operatorname{arc} 1^{-}$strain. Yeast Los1p is a nuclear export factor for tRNA. $^{38,39}$ However, LOS1 is a non-essential gene which provides strong evidence for the existence of parallel tRNA nuclear export pathways in yeast. ARC1 is synthetically lethal upon the disrup- tion of LOS1, which led to the suggestion that Arc1p might also be directly involved in tRNA export. ${ }^{40}$ However, all the available data strongly suggest that Arc1p is efficiently sequestered in the cytoplasm of yeast. In an exhaustive study, Galani et al. ${ }^{25}$ showed that Arc1p, MetRS and GluRS are excluded from the nucleus unless the Arc1pMetRS-GluRS complex is disrupted. Therefore, the emergence of this ternary complex can be seen as a means to prevent leakage of these enzymes into the nuclear compartment, and thus to confine components of the translational apparatus to the cytoplasm, where translation occurs.

All models of nuclear tRNA export in yeast already published are based on the idea that tRNA aminoacylation can occur in the nucleus, and that a Los1p-independent pathway is directly linked to nuclear tRNA aminoacylation. ${ }^{41}$ In support of these hypotheses, temperature-sensitive (ts) mutations of three different aminoacyl-tRNA synthetases (mes1-1, ils1-1 and tys1-1 encoding thermosensitive methionyl-, isoleucyl- and tyrosyltRNA synthetases, respectively) were accompanied by a nuclear accumulation of tRNAs. ${ }^{42}$ Likewise, at non-permissive temperature, tRNA accumulation inside the nucleus is observed in a cca1-1 ts mutant that encodes a thermosensitive tRNA nucleotidyltransferase, an essential enzyme involved in CCA addition at the $3^{\prime}$ end of tRNA molecules. ${ }^{41,42}$ Moreover, accumulation of non-aminoacylated tRNAs by amino acid starvation or by addition of specific inhibitors, or of free aminoacylated tRNAs in cells with reduced amounts of EF1A or with mutant alleles of TEF2 resulted in nuclear accumulation of tRNA. Therefore, strains that are defective for tRNA aminoacylation or for formation of the ternary complex EF1A-GTP-aatRNA show accumulation of tRNA inside the nucleus. Taken nuclear aminoacylation for granted, these results have been interpreted as the requirement for aminoacylation and EF1A for nuclear tRNA export. ${ }^{41}$ However, nuclear EF1A has never been observed and the presence of aminoacyl-tRNA synthetases in the nuclear compartment remains a controversial question. It should also be noticed that inhibition of protein synthesis by means that would not affect the capacity of tRNA to associate with major cytoplasmic proteins has no effect on tRNA compartmentalization within the cell. For instance, mutations in the genes encoding eIF2 $\gamma$, the $\gamma$ subunit of the eukaryotic initiation factor 2 that binds $\mathrm{tRNA}_{\mathrm{i}}^{\mathrm{Met}}$, or eIF2B $\gamma$, the $\gamma$ subunit of the guanine nucleotide exchange factor for eIF2, are synthetically lethal with a LOS1 deletion. ${ }^{38} \mathrm{How}^{-}$ ever, nuclear accumulation of tRNA could not be detected in the sui2-1 ts mutant of eIF $2 \alpha$, in strains with $g c d 11$ mutant alleles of eIF2 $\gamma$ or in the $g c d 1$ 501 ts mutant of eIF2B $\gamma .{ }^{41}$ Similarly, treatment of cells with cycloheximide that blocks ribosomal protein synthesis and causes accumulation of the ternary complex EF1A-GTP-aatRNA did not result in nuclear accumulation of tRNA. ${ }^{41}$ Thus, when translation is blocked at the initiation step 
or at the ribosomal elongation stage, two processes that do not affect the level of tRNA aminoacylation in vivo and that do not impair formation of the ternary complex EF1A-GTP-aatRNA, tRNA is not preferentially recruited in the nuclear compartment.

As discussed by Görlich and co-workers, ${ }^{43}$ nuclear transport pathways seem to synergize to confine protein components of the translation machinery to the cytoplasm of eukaryotic cells. One alternative explanation to the data recapitulated above is to consider that aminoacyl-tRNA is confined to the cytoplasm via protein-tRNA interactions and that tRNAs in excess that are not trapped in the cytoplasm by components of the translation machinery are able to diffuse (or to be transported) to the nuclear compartment. Accordingly, overexpression of ScMetRS suppressed the nuclear accumulation of $\mathrm{tRNA}^{\mathrm{Met}}$ observed in a strain with a los 1 null mutation ${ }^{44}$ and overproduction of eEF1A also restored growth of the synthetically lethal $\operatorname{los} 1^{-} \operatorname{arc} 1 \Delta \mathrm{C}$ strain. ${ }^{41}$ Similarly, because p43 and Arc1p are potent tRNA binding proteins per se, they might confine tRNA to the cytoplasm thereby increasing the concentration of tRNA available for protein synthesis. The possible substitution of Arc1p by its human homolog p43 will allow us to address the involvement of p43/Arc1p in the sequestration of tRNA in the cytoplasm of yeast independently of their role of tIF for two aminoacyl-tRNA synthetases.

\section{Materials and Methods}

\section{DNA manipulations, yeast strains, and media}

All recombinant DNA manipulations were carried out using standard protocols. ${ }^{45}$ Restriction endonucleases and DNA modification enzymes were purchased from either Roche, or New England Biolabs. Nucleotide sequences were determined by automatic sequencing (MWG Biotech). The following previously described plasmids were used: pRS314 (CEN/ARS, TRP1), pRS315

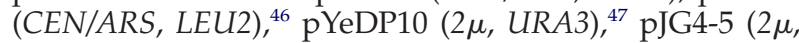
TRP1), ${ }^{48}$ pRS316-URA3-MetRS (CEN/ARS, URA3) expressing S.cerevisiae MetRS (ScMetRS), ${ }^{25}$ pUN100Arc1 (CEN/ARS, LEU2) expressing S. cerevisiae Arc1p, ${ }^{20}$ pRS425-ProtA-Arc1 (2 $\mu$, LEU2) expressing S. cerevisiae Arc1p fused to protein A at its N-terminal end (ProtAArclp) (K. Galani \& G. Simos, unpublished results), and pYeDP60-ArgRS $(2 \mu, U R A 3, A D E 2)$ expressing hamster ArgRS. ${ }^{49}$ The yeast strains used in this study were: $\operatorname{los} 1^{-}$ $\operatorname{arc1}^{-}$(a, los1:: HIS3, arc1:: HIS3, ade2, leu2, ura3, trp1, his3, pHT4467-URA3-ADE3-LOS1), ${ }^{20}$ mes1 $^{-} \operatorname{arc1}^{-}$(a, mes1::HIS5, arc1::HIS3, ade2, leu2, ura3, trp1, his3, pRS316-URA3-MetRS), ${ }^{25}$ and W303-1B ( $\alpha$, leu2, his3, trp1, ura3, ade2). Yeast cells were transformed using the lithium chloride method ${ }^{50}$ and were grown in rich YPG medium $(0.5 \%(\mathrm{w} / \mathrm{v})$ yeast extract, $0.5 \%(\mathrm{w} / \mathrm{v})$ Bacto peptone, $3 \%(\mathrm{w} / \mathrm{v})$ glucose $)$ or in minimal YNB medium $(0.7 \%(\mathrm{w} / \mathrm{v})$ yeast nitrogen base without amino acids, $2 \%$ glucose) containing the necessary amino acids and bases except those used for selection. For protein expression, cultures were performed in YPG or YNB medium; for ArgRS expression, cultures were performed in YPGal medium $(0.5 \%$ yeast extract, $0.5 \%$ Bacto peptone, $2 \%$ $(\mathrm{w} / \mathrm{v})$ galactose $)$ containing tryptophan.

\section{Construction of yeast expression vectors}

Proteins were expressed in yeast under the control of the PGK promoter except Arc1p and ProtA-Arc1p (ADH1 promoter), ScMetRS (MES1 natural promoter), and hamster ArgRS (GAL10-CYC1 promoter). The pPGK-tPGK cassette was excised from pYeDP10 by BamHI/EcoRI digestion and inserted into the BamHI/ EcoRI sites of pRS314 (pRS314-pPGK-tPGK), and the BamHI/HindIII sites of pRS315 (pRS315-pPGK-tPGK). The SacI/EcoRI cassette containing pPGK and tPGK of pRS314-pPGK-tPGK was inserted into the SacI/SphI sites of pJG4-5 (pJG4-5-pPGK-tPGK).

\section{Cloning of the different MetRSs in yeast expression vectors}

Using pYeDP10 plasmid as template, the BgIII/SnaBI fragment of tPGK was amplified by PCR and EcoRI/ SalI sites were introduced at the $3^{\prime}$ end of the sequence. After BgIII/SalI digestion, tPGK was introduced into the XhoI site following the stop codon of pET-28b-MOs $\Delta \mathrm{C}$ plasmid (pET-28b-MOs $\Delta$ C-tPGK*) expressing the catalytic core of the plant O. sativa MetRS (OsMetRS; GenBank GI 4091007) deleted of the seven proline residues located at positions 4-10 and truncated of its $\mathrm{M}$ and C-terminal domains (stop codon introduced just after the Glu codon at position 593), OsMetRS $\Delta(\mathrm{M}+\mathrm{C})^{16,27}$ (Figure 1). The HindIII/XhoI fragment was PCR-amplified and a Xhol site followed by a stop codon and a Sall site were introduced just after the Glu593 codon. After HindIII/ Sall digestion, the PCR product was inserted into the HindIII/XhoI sites of pET-28b-MOs $\Delta$ C-tPGK* (pET-28bMOs $\Delta \mathrm{C}^{*}$-tPGK*).

The $(\mathrm{M}+\mathrm{C})$-terminal domain of $O$. sativa MetRS was PCR-amplified from the M13-MOs43-2 plasmid $^{27}$ (Figure 1) and XhoI sites were introduced at the $5^{\prime}$ and $3^{\prime}$ ends of the sequence. The C-terminal domain of Homo sapiens MetRS (HsMetRS; GenBank GI 14043021; Figure 1) was excised from pET-28b-MHs plasmid ${ }^{15}$ by Sall/Xhol digestion. The C domain (residues 201-376) and the $(\mathrm{M}+\mathrm{C})$ domain (residues 132-376) of S. cerevisiae Arc1p (GenBank GI 1620459; Figure 1) were PCR-amplified from pUN100-Arc1 plasmid and SalI and XhoI sites were introduced at the $5^{\prime}$ and $3^{\prime}$ ends, respectively. The $\mathrm{C}$ domain (residues 147-312) and $(\mathrm{M}+\mathrm{C})$ domain (residues 107-312) of H. sapiens p43 (GenBank GI 4758265; Figure 1) were PCR-amplified from pET-28bp43 plasmid $^{30}$ and XhoI sites were introduced at the $5^{\prime}$ and $3^{\prime}$ ends of the sequence. After XhoI or SalI/XhoI digestion of the PCR products, $\mathrm{C}$ or $(\mathrm{M}+\mathrm{C})$ domain cassettes were inserted into the XhoI site of pET-28b$\mathrm{MOs} \Delta \mathrm{C} *-\mathrm{tPGK} *$ to construct the different pET-28bMOs $\Delta \mathrm{C} *-$-Xdomain-tPGK $*$ plasmids expressing OsMetRS $\Delta(\mathrm{M}+\mathrm{C})-\mathrm{X}$ domain proteins. The different $\mathrm{X}$ domains fused to the C-terminal end of OsMetRSA $(\mathrm{M}+$ C) are: the $C$ and $(M+C)$ domains of yeast Arc1p noted CArc1 and $(M+C) A r c 1$, respectively; the $C$ and $(\mathrm{M}+\mathrm{C})$ domains of human p43 noted $\mathrm{Cp} 43$ and $(\mathrm{M}+\mathrm{C}) \mathrm{p} 43$, respectively; and the $\mathrm{C}$ domain of HsMetRS noted $\mathrm{CHsMetRS.} \mathrm{Native} \mathrm{plant} \mathrm{MetRS,} \mathrm{corresponding} \mathrm{to}$ the natural fusion of $\operatorname{OsMetRS} \Delta(\mathrm{M}+\mathrm{C})$ with its $(\mathrm{M}+\mathrm{C})$ domain (Figure 1) is noted OsMetRS.

The NcoI/NdeI fragment of pET-28b-MOs was introduced into the BglII site of pRS314-pPGK-tPGK vector 
(pRS314-5'MOs-tPGK). pRS314-MOs $\Delta \mathrm{C}^{*}-\mathrm{X}$ domain plasmids were produced by BglII digestion of pRS3145'MOs-tPGK, EagI/EcoRI digestion of the pET-28bMOs $\Delta C^{*}$-Xdomain-tPGK ${ }^{*}$ plasmids or of pET-28bMOs $\Delta$ C-tPGK ${ }^{*}$ plasmid, and recombination in yeast. pRS315-MOs $\Delta \mathrm{C}$ (and pRS315-MOs $\Delta \mathrm{C}^{*}-\mathrm{CH}$ sMetRS) and pJG4-5-MOs $\Delta \mathrm{C}$ (and pJG4-5-MOs $\Delta \mathrm{C}^{*}$-CHsMetRS) plasmids were produced by $\mathrm{XbaI} / \mathrm{EcoRI}$ digestion of pRS314-MOs $\Delta \mathrm{C}$ (and pRS314-MOs $\Delta \mathrm{C}^{*}-\mathrm{CH}$ sMetRS), BglII digestion of pRS315-pPGK-tPGK and pJG4-5pPGK-tPGK, and recombination in yeast.

\section{Expression of human p43 and EF1A in yeast}

pRS315-p43 expressing human p43 was constructed by insertion of the BamHI/XbaI fragment of pTRE2-p43 plasmid (V. Shalak \& M.M., unpublished results) into the BglII site of pRS315-pPGK-tPGK vector. The pJG4-5p43 plasmid was constructed by BamHI/EcoRI digestion of pRS315-p43, BglII digestion of pJG4-5-pPGK-tPGK and recombination in yeast. pRS315-EF1A expressing human EF1A was constructed by insertion of the NdeI/ BamHI fragment of pET-16b-EF1A plasmid (gift from Jan Dijk, Leiden, The Netherlands) into the BglII site of pRS315-pPGK-tPGK plasmid.

\section{Complementation assays}

los $1^{-} \operatorname{arcl}^{-}$and $\mathrm{mes}^{-} \mathrm{arc1}^{-}$yeast strains transformed with the desired plasmid(s) were grown overnight to 40 hours in YNB medium containing all the necessary amino acids and bases including uracil. For counter selection for cells containing URA3 plasmids, the cultures were typically diluted to an optical density at $600 \mathrm{~nm}$ of 1 and $50 \mu \mathrm{l}$ were plated on an YNB agar plate containing uracil, 5'-fluoroorotic acid (FOA; Euromedex) at $1 \mathrm{mg} / \mathrm{ml}$ and the necessary amino acids and bases except those used for selection. Plates were incubated for four to six days at $28^{\circ} \mathrm{C}$.

\section{Yeast growth studies in liquid medium}

Overnight pre-culture of the desired yeast strain was performed at $28^{\circ} \mathrm{C}$ in YNB medium containing all the necessary amino acids and bases. Cultures were performed at the desired temperature in YPG containing adenine and tryptophan (if necessary) and were inoculated with YNB pre-culture. After 12-15 hours, aliquots were removed and absorbances at $600 \mathrm{~nm}$ were measured. For each culture, the absorbance at $600 \mathrm{~nm}$ was plotted as a function of time and data were fitted with a single-exponential equation using KaleidaGraph Software. The doubling-time $(\tau)$ was calculated from the parameter of the exponential fit. To be able to compare results of experiments performed at different days, they were normalized using one strain as reference.

\section{Yeast growth studies on agar plate}

Overnight culture of the desired yeast strain was grown at $28^{\circ} \mathrm{C}$ in YNB medium containing all the necessary amino acids and bases. Absorbances at $600 \mathrm{~nm}$ were measured and cultures were diluted to an absorbance of 0.3 . Serial dilutions were made with a dilution factor of 4 . For each culture and dilution, a $6 \mu \mathrm{l}$ drop was deposited on an YPG plate containing adenine and tryptophan. Plates were incubated at the temperature and for the time specified in the text.

\section{p43 immunoprecipitation}

Cells were grown in $150 \mathrm{ml}$ of YNB (or YPGal for ArgRS expression) to an optical density at $600 \mathrm{~nm}$ of 1 . Cultures were centrifuged, and cells were washed with extraction buffer (100 mM Tris- $\mathrm{HCl}(\mathrm{pH} 8.0), 10 \mathrm{mM}$ $\mathrm{MgCl}_{2}, 1 \mathrm{mM} \mathrm{DTT}$ ) and resuspended in $0.6 \mathrm{ml}$ of extraction buffer. Cells were broken mechanically with glass beads, centrifuged, and supernatants were collected and kept on ice. A $2 \mu \mathrm{M}$ solution of His-tagged human $\mathrm{p} 43^{30}$ in A50T buffer $\left(8 \mathrm{mM} \mathrm{Na} \mathrm{HPO}_{4}, 15 \mathrm{mM} \quad \mathrm{KH}_{2} \mathrm{PO}_{4}\right.$ $2.7 \mathrm{mM} \mathrm{KCl}, 50 \mathrm{mM} \mathrm{NaCl}, 0.1 \%$ (v/v) Triton X-100) containing $0.2 \%(\mathrm{w} / \mathrm{v})$ of bovine serum albumin was prepared. A total of $100 \mu$ l of yeast extract was incubated for 30 minutes at $4{ }^{\circ} \mathrm{C}$ with $50 \mu \mathrm{l}$ of His-tagged p43 solution or with $50 \mu \mathrm{l}$ of A50T-BSA buffer (control). A pre-adsorption step was performed: $10 \mu \mathrm{l}$ of a $6.8 \mathrm{mg} /$ $\mathrm{ml}$ solution of goat IgG was added to each sample. After 15 minutes at $4{ }^{\circ} \mathrm{C}, 20 \mu \mathrm{l}$ of a $1: 1$ slurry of protein A-Sepharose (Amersham Biosciences) in A50T buffer was added. After 30 minutes at $4{ }^{\circ} \mathrm{C}$, samples were pelleted by centrifugation and supernatants were recovered. The specific immunoprecipitation step was conducted by the addition of $10 \mu \mathrm{l}$ of a $100 \mu \mathrm{g} / \mathrm{ml}$ of penta-His antibody (Qiagen). After one hour at $4{ }^{\circ} \mathrm{C}, 25 \mu \mathrm{l}$ of a $1: 1$ slurry of protein A-Sepharose in A50T buffer were added. After 30 minutes at $4{ }^{\circ} \mathrm{C}$, samples were pelleted by centrifugation and supernatants removed. Pellets were washed five times with $1 \mathrm{ml}$ of A100T buffer (A50T containing $100 \mathrm{mM} \mathrm{NaCl}$ ) and once with $1 \mathrm{ml}$ of $10 \mathrm{mM}$ Tris- $\mathrm{HCl}(\mathrm{pH} \mathrm{7.5)}$. Samples were analyzed by SDS-PAGE on a $10 \%(\mathrm{w} / \mathrm{v})$ polyacrylamide gel..$^{51}$ ScMetRS, ScGluRS, hamster ArgRS and OsMetRSA(M + C)- $(M+C) p 43$ proteins were detected by Western blotting using antibodies raised against ScMetRS or ScGluRS (gifts from Franco Fasiolo, Strasbourg, France), against the catalytic domain of hamster ArgRS, ${ }^{49}$ or against the C-terminal domain of $\mathrm{p} 43 .{ }^{30}$

\section{Interaction of ProtA-Arc1p with MetRS and GluRS}

arc $1^{-}$mes $1^{-}$cells co-expressing ProtA-Arc1p and ScMetRS (interaction of Arc1p with ScMetRS and ScGluRS) or OsMetRS $\Delta(\mathrm{M}+\mathrm{C})-(\mathrm{M}+\mathrm{C}) \mathrm{p} 43$ were grown overnight in $150 \mathrm{ml}$ of YNB. Negative controls were performed with cells expressing one of the two MetRS (ScMetRS or OsMetRS $\Delta(\mathrm{M}+\mathrm{C})-(\mathrm{M}+\mathrm{C}) \mathrm{p} 43)$ only (no co-expression of ProtA-Arc1p). Yeast extracts were prepared as described above; $100 \mu \mathrm{l}$ of extract were incubated for one hour with $50 \mu \mathrm{l}$ of IgG-Sepharose (Amersham Biosciences). After one hour at $4{ }^{\circ} \mathrm{C}$, samples were centrifuged and supernatants removed. Pellets were washed five times with $1 \mathrm{ml}$ of A100T buffer and once with $1 \mathrm{ml}$ of $10 \mathrm{mM}$ Tris- $\mathrm{HCl}$ (pH 7.5). Samples were analyzed by SDS-PAGE on a $10 \%$ polyacrylamide gel. Proteins were detected by Western blotting.

\section{Aminoacylation assay}

OsMetRS $\Delta(\mathrm{M}+\mathrm{C})$ and $\mathrm{p} 43$ were purified as described..$^{16,30}$ OsMetRS $\Delta(\mathrm{M}+\mathrm{C}) \quad(0.1 \mu \mathrm{M})$ was preincubated at $4{ }^{\circ} \mathrm{C}$ for 20 minutes with p43 $(0,0.1$ or $1.0 \mu \mathrm{M})$ in $10 \mathrm{mM}$ Tris- $\mathrm{HCl}(\mathrm{pH} 7.5), 10 \mathrm{mM}$ 2-mercaptoethanol, and bovine serum albumin at $4 \mathrm{mg} / \mathrm{ml}$. Time course of aminoacylation of tRNA $A_{i}^{\text {Met }}$ was conducted at $25^{\circ} \mathrm{C}$. tRNA aminoacylation was performed in $20 \mathrm{mM}$ imidazole- $\mathrm{HCl}$ buffer ( $\mathrm{pH} 7.5), 100 \mathrm{mM} \mathrm{KCl}$, $0.5 \mathrm{mM}$ DTT, $7 \mathrm{mM} \mathrm{MgCl} 2,2 \mathrm{mM}$ ATP, $60 \mu \mathrm{M}{ }^{14} \mathrm{C}$-labeled 
methionine (NEN; $50 \mathrm{Ci} / \mathrm{mol})$ and non-saturating amounts of tRNA $(1 \mu \mathrm{M})$ as described. ${ }^{16}$ Homogeneous yeast tRNA $_{\mathrm{i}}^{\text {Met }}$ obtained by in vitro transcription ${ }^{16}$ (methionine acceptance of $1150 \mathrm{pmol} / A_{260}$ ) was used as tRNA substrate. The reaction mixture contained catalytic amounts of OsMetRS $\Delta(\mathrm{M}+\mathrm{C})(10 \mathrm{nM})$ and increasing amounts of human p43 (0,10 or $100 \mathrm{nM})$. At different time intervals, aliquots were withdrawn, quenched in ice-cold $5 \%(\mathrm{w} / \mathrm{v})$ trichloroacetic acid, filtered on GF/C filters (Whatman) and processed for liquid scintillation counting.

\section{Acknowledgements}

We acknowledge the technical assistance of Françoise Triniolles and Florence Ruaudel and thank K. Galani and G. Simos (Heidelberg, Germany and Larissa, Greece) for the gifts of pRS316-URA3-MetRS, pUN100-Arc1 and pRS425ProtA-Arc1 plasmids and of mes1- arc1 $^{-}$and los $1^{-} \operatorname{arc1}^{-}$yeast strains; J. Dijck (Leiden, The Netherlands) for the gift of pET-16b-Hs EF1A; and F. Fasiolo (Strasbourg, France) for the gift of antibodies directed to ScMetRS and ScGluRS. A.Z. was supported by a grant from the Jumelage Franco-Polonais program from the CNRS.

\section{References}

1. Ibba, M. \& Söll, D. (2000). Aminoacyl-tRNA synthesis. Annu. Rev. Biochem. 69, 617-650.

2. Schimmel, P. \& Söll, D. (1979). Aminoacyl-tRNA synthetases: general features and recognition of transfer RNAs. Annu. Rev. Biochem. 48, 601-648.

3. Ebel, J. P., Giegé, R., Bonnet, J., Kern, D., Befort, N., Bollack, C. et al. (1973). Factors determining the specificity of the tRNA aminoacylation reaction. Biochimie, 55, 547-557.

4. Schimmel, P., Giegé, R., Moras, D. \& Yokoyama, S. (1993). An operational RNA code for amino acids and possible relationship to genetic code. Proc. Natl Acad. Sci. USA, 90, 8763-8768.

5. Buechter, D. D. \& Schimmel, P. (1993). Aminoacylation of RNA minihelices-implications for tRNA synthetase structural design and evolution. CRC Crit. Rev. Biochem. 28, 309-322.

6. Mirande, M. (1991). Aminoacyl-tRNA synthetase family from prokaryotes and eukaryotes: structural domains and their implications. Prog. Nucl. Acid Res. Mol. Biol. 40, 95-142.

7. Lazard, M. \& Mirande, M. (1993). Cloning and analysis of a cDNA encoding mammalian arginyl-tRNA synthetase, a component of the multisynthetase complex with a hydrophobic N-terminal extension. Gene, 132, 237-245.

8. Frugier, M., Moulinier, L. \& Giegé, R. (2000). A domain in the N-terminal extension of class $\mathrm{Ilb}$ eukaryotic aminoacyl-tRNA synthetases is important for tRNA binding. EMBO J. 19, 2371-2380.

9. Beaulande, M., Kron, M. \& Härtlein, M. (2001). Human anti-asparaginyl-tRNA synthetase autoantibodies (anti-KS) increase the affinity of the enzyme for its tRNA substrate. FEBS Letters, 494, 170-174.

10. Hammamieh, R. \& Yang, D. C. H. (2001). Magnesium ion-mediated binding to tRNA by an amino-terminal peptide of a class II tRNA synthetase. J. Biol. Chem. 276, 428-433.

11. Francin, M., Kaminska, M., Kerjan, P. \& Mirande, M. (2002). The N-terminal domain of mammalian lysyltRNA synthetase is a functional tRNA-binding domain. J. Biol. Chem. 277, 1762-1769.

12. Cahuzac, B., Berthonneau, E., Birlirakis, N., Guittet, E. \& Mirande, M. (2000). A recurrent RNA-binding domain is appended to eukaryotic aminoacyl-tRNA synthetases. EMBO J. 19, 445-452.

13. Berthonneau, E. \& Mirande, M. (2000). A gene fusion event in the evolution of aminoacyl-tRNA synthetases. FEBS Letters, 470, 300-304.

14. Cérini, C., Kerjan, P., Astier, M., Gratecos, D., Mirande, M. \& Semeriva, M. (1991). A component of the multisynthetase complex is a multifunctional aminoacyl-tRNA synthetase. EMBO J. 10, 4267-4277.

15. Kaminska, M., Shalak, V. \& Mirande, M. (2001). The appended C-domain of human methionyl-tRNA synthetase has a tRNA-sequestering function. Biochemistry, 40, 14309-14316.

16. Kaminska, M., Deniziak, M., Kerjan, P., Barciszewski, J. \& Mirande, M. (2000). A recurrent general RNA binding domain appended to plant methionyl-tRNA synthetase acts as a cis-acting cofactor for aminoacylation. EMBO J. 19, 6908-6917.

17. Kleeman, T. A., Wei, D. B., Simpson, K. L. \& First, E. A. (1997). Human tyrosyl tRNA synthetase shares amino acid sequence homology with a putative cytokine. J. Biol. Chem. 272, 14420-14425.

18. Quevillon, S., Agou, F., Robinson, J. C. \& Mirande, M. (1997). The p43 component of the mammalian multi-synthetase complex is likely to be the precursor of the endothelial monocyte-activating polypeptide II cytokine. J. Biol. Chem. 272, 32573-32579.

19. Kao, J., Ryan, J., Brett, G., Chen, J., Shen, H., Fan, Y. G. et al. (1992). Endothelial monocyte-activating polypeptide II. A novel tumor-derived polypeptide that activates host-response mechanisms. J. Biol. Chem. 267, 20239-20247.

20. Simos, G., Segref, A., Fasiolo, F., Hellmuth, K., Shevchenko, A., Mann, M. \& Hurt, E. C. (1996). The yeast protein Arclp binds to tRNA and functions as a cofactor for the methionyl- and glutamyl-tRNA synthetases. EMBO J. 15, 5437-5448.

21. Deinert, K., Fasiolo, F., Hurt, E. C. \& Simos, G. (2001). Arc1p organizes the yeast aminoacyl-tRNA synthetase complex and stabilizes its interaction with the cognate tRNAs. J. Biol. Chem. 276, 6000-6008.

22. Cassio, D. \& Waller, J. P. (1971). Modification of E. coli methionyl-tRNA synthetase by proteolytic cleavage and properties of the trypsin modified enzyme. Eur. J. Biochem. 20, 283-300.

23. Mellot, P., Mechulam, Y., Le Corre, D., Blanquet, S. \& Fayat, G. (1989). Identification of an amino acid region supporting specific methionyl-tRNA synthetase: tRNA recognition. J. Mol. Biol. 208, 429-443.

24. Simos, G., Sauer, A., Fasiolo, F. \& Hurt, E. C. (1998). A conserved domain within Arc1p delivers tRNA to aminoacyl-tRNA synthetases. Mol. Cell, 1, 235-242.

25. Galani, K., Grosshans, H., Deinert, K., Hurt, E. C. \& Simos, G. (2001). The intracellular location of two aminoacyl-tRNA synthetases depends on complex formation with Arc1p. EMBO J. 20, 6889-6898.

26. Simos, G., Tekotte, H., Grosjean, H., Segref, A., Sharma, K., Tollervey, D. \& Hurt, E. C. (1996). Nuclear pore proteins are involved in the biogenesis of functional tRNA. EMBO J. 15, 2270-2284. 
27. Deniziak, M., Mirande, M. \& Barciszewski, J. (1998). Cloning and sequencing of cDNA encoding the rice methionyl-tRNA synthetase. Acta Biochim. Pol. 45, 669-676.

28. Kerjan, P., Cérini, C., Semeriva, M. \& Mirande, M. (1994). The multienzyme complex containing nine aminoacyl-tRNA synthetases is ubiquitous from Drosophila to mammals. Biochim. Biophys. Acta, 1199, 293-297.

29. Renault, L., Kerjan, P., Pasqualato, S., Menetrey, J., Robinson, J. C., Kawaguchi, S. et al. (2001). Structure of the EMAPII domain of human aminoacyl-tRNA synthetase complex reveals evolutionary dimer mimicry. EMBO J. 20, 570-578.

30. Shalak, V., Kaminska, M., Mitnacht-Kraus, R., Vandenabeele, P., Clauss, M. \& Mirande, M. (2001). The EMAPII cytokine is released from the mammalian multisynthetase complex after cleavage of its p43/proEMAPII component. J. Biol. Chem. 276, 23769-23776.

31. Robinson, J. C., Kerjan, P. \& Mirande, M. (2000). Macromolecular assemblage of aminoacyl-tRNA synthetases: quantitative analysis of protein-protein interactions and mechanism of complex assembly. J. Mol. Biol. 304, 983-994.

32. Hurt, D. J., Wang, S. S., Lin, Y. H. \& Hopper, A. K. (1987). Cloning and characterization of LOS1, a Saccharomyces cerevisiae gene that affects tRNA splicing. Mol. Cell. Biol. 7, 1208-1216.

33. Hopper, A. K., Schultz, L. D. \& Shapiro, R. A. (1980). Processing of intervening sequences: a new yeast mutant which fails to excise intervening sequences from precursor tRNAs. Cell, 19, 741-751.

34. Whelihan, E. F. \& Schimmel, P. (1997). Rescuing an essential enzyme RNA complex with a non-essential appended domain. EMBO J. 16, 2968-2974.

35. Wang, C. C. \& Schimmel, P. (1999). Species barrier to RNA recognition overcome with non-specific RNA binding domains. J. Biol. Chem. 274, 16508-16512.

36. Chihade, J. W. \& Schimmel, P. (1999). Assembly of a catalytic unit for RNA microhelix aminoacylation using nonspecific RNA binding domains. Proc. Natl Acad. Sci. USA, 96, 12316-12321.

37. Wang, C. C., Morales, A. J. \& Schimmel, P. (2000). Functional redundancy in the non-specific RNA binding domain of a class I tRNA synthetase. J. Biol. Chem. 275, 17180-17186.

38. Hellmuth, K., Lau, D. M., Bischoff, F. R., Kunzler, M., Hurt, E. \& Simos, G. (1998). Yeast Los1p has proper- ties of an exportin-like nucleocytoplasmic transport factor for tRNA. Mol. Cell. Biol. 18, 6374-6386.

39. Hopper, A. K. \& Phizicky, E. M. (2003). tRNA transfers to the limelight. Genes Dev. 17, 162-180.

40. Grosshans, H., Simos, G. \& Hurt, E. (2000). Transport of tRNA out of the nucleus-direct channeling to the ribosome? J. Struct. Biol. 129, 288-294.

41. Grosshans, H., Hurt, E. \& Simos, G. (2000). An aminoacylation-dependent nuclear tRNA export pathway in yeast. Genes Dev. 14, 830-840.

42. Sarkar, S., Azad, A. K. \& Hopper, A. K. (1999). Nuclear tRNA aminoacylation and its role in nuclear export of endogenous tRNAs in Saccharomyces cerevisiae. Proc. Natl Acad. Sci. USA, 96, 14366-14371.

43. Bohnsack, M. T., Regener, K., Schwappach, B., Saffrich, R., Paraskeva, E., Hartmann, E. \& Görlich, D. (2002). Exp5 exports eEF1A via tRNA from nuclei and synergizes with other transport pathways to confine translation to the cytoplasm. EMBO J. 21, 6205-6215.

44. Feng, W. Q. \& Hopper, A. K. (2002). A Los1p-independent pathway for nuclear export of intronless tRNAs in Saccharomyces cerevisiae. Proc. Natl Acad. Sci. USA, 99, 5412-5417.

45. Sambrook, J., Fritsch, E. F. \& Maniatis, T. (1989). Molecular Cloning: A Laboratory Manual, 2nd edit., Cold Spring Harbor Laboratory Press, Cold Spring Harbor, NY.

46. Sikorski, R. S. \& Hieter, P. (1989). A system of shuttle vectors and yeast host strains designed for efficient manipulation of DNA in Saccharomyces cerevisiae. Genetics, 122, 19-27.

47. Urban, P., Cullin, C. \& Pompon, D. (1990). Maximizing the expression of mammalian cytochrome P-450 monooxygenase activities in yeast cells. Biochimie, 72, 463-472.

48. Gyuris, J., Golemis, E., Chertkov, H. \& Brent, R. (1993). Cdi1, a human G1 and S phase protein phosphatase that associates with Cdk2. Cell, 75, 791-803.

49. Lazard, M., Kerjan, P., Agou, F. \& Mirande, M. (2000). The tRNA-dependent activation of arginine by arginyl-tRNA synthetase requires inter-domain communication. J. Mol. Biol. 302, 991-1004.

50. Ito, H., Fukuda, Y., Murata, K. \& Kimura, A. (1983). Transformation of intact yeast cells treated with alkali cations. J. Bacteriol. 153, 163-168.

51. Laemmli, U. K. (1970). Cleavage of structural proteins during the assembly of the head of Bacteriophage T4. Nature, 227, 680-685.

Edited by J. Karn 